\title{
Article
}

\section{Near/Mid IR Differential Absorption OPO Lidar System for Gas Analysis of the Atmosphere}

\author{
Oleg A. Romanovskii ${ }^{1,2, *}$, Sergey A. Sadovnikov ${ }^{1}$, Olga V. Kharchenko ${ }^{1}$ and \\ Semen V. Yakovlev ${ }^{1,2}$ \\ 1 V.E. Zuev Institute of Atmospheric Optics, Siberian Branch, Russian Academy of Sciences, Acad. Zuev Sq. \\ 1, Tomsk, 634055, Russia; roa@iao.ru (O.R.); sadsa@iao.ru (S.S.); olya@iao.ru (O.K.); ysv@iao.ru (S.Y.) \\ 2 National Research Tomsk State University, Lenin Ave. 36, Tomsk, 634050, Russia; roa@iao.ru (O.R.); \\ ysv@iao.ru (S.Y.) \\ * Correspondence: roa@iao.ru ; Tel.: +7-913-868-4294
}

\begin{abstract}
Data on the atmospheric gas concentrations can be received with high efficiency and on a large spatial scale only from remote laser sounding instruments. The remote laser techniques with the use of lidars are widely used in the study of the atmosphere and control of its state. The aims of this work are the design and test in numerical and field experiments of a DIAL OPO lidar system based on KTA and KTP crystals for gas analysis of the atmosphere. Lidar measurements of atmospheric gases in the near/mid infrared region have been numerically simulated. The differential absorption lidar system based on optical parametric oscillators with nonlinear KTA and KTP crystals which allow laser radiation tuning both in the near and in the middle IR spectral region is described; it allows tuning laser radiation in the near/mid-IR wavelength regions. Lidar echo signals have been experimentally recorded in the $1.8-2.5$ and 3-4 $\mu \mathrm{m}$ wavelength ranges. The results of $\mathrm{H}_{2} \mathrm{O}$ and $\mathrm{CO}_{2}$ profile measurements along the surface sounding path are presented.
\end{abstract}

Keywords: lidar, atmosphere, DIAL, optical parametric oscillator, trace gases

\section{Introduction}

The The problem of remote monitoring of atmospheric gases and detection of dangerous gases is topical in view of needs in avoiding technogenic threats and counterterrorism. Dangerous impurities propagate in the atmosphere quicker than in other natural media; therefore, local catastrophes turn into regional and global (Chernobyl, Fukushima, emissions in Seversk in 1993, etc.). Data on the atmospheric gas concentrations can be received with high efficiency and on a large spatial scale only from remote laser sounding instruments. The remote laser techniques with the use of lidars are widely used in the study of the atmosphere and control of its state [1 - 4].

The spectra of vapors of most atmospheric gases have quite strong lines in the wavelength range from 1.5 to $4 \mu \mathrm{m}$, which determines the information content of this spectral range for the lidar gas analysis.

In the near/mid-IR spectral region, the rotational-vibrational (RV) absorption spectra of molecules of atmospheric gases highly specific due to their symmetry and chemical composition, which makes possible quite accurate assignment of individual spectral lines to a well-defined chemical compound. Just this spectral region includes the fundamental RV transitions of molecules of almost all atmospheric gases. Thus, the near/mid-IR are of great interest for the practical implementation of remote monitoring of hazardous substances in the atmosphere.

There are several techniques for the study and detection of atmospheric gases, among which a special place is occupied by the technique for remote detection and identification of gas traces based on selective radiation absorption. This technique has maximal sensitivity when sounding gases at large distances (differential absorption, or DIAL).

The problem of the practical implementation of DIAL today is the lack of sufficiently high-power highly monochromatic laser sources in the near/mid-IR, which allow smooth and/or 
discrete tuning of the radiation frequency. One of the approaches to generation of tunable laser radiation in these regions is the use of parametric laser frequency converters based on nonlinear optical crystals, which are actively applied to generation of laser radiation [5] and harmonics of different orders [6], for optical rectification, frequency mixing [7], etc. Laser systems based on them are characterized by highly stable radiation characteristics, small sizes, and a capability of quick changing the laser configuration (variability of components) and, which is extremely important, a possibility of smooth tuning of the radiation wavelength in a wide spectral range [8].

To cover the near/mid-IR spectral region, radiation of optical parametric oscillators (OPO) based on nonlinear crystals is used [9-14].

The authors of work [9] present a lidar system unique in functionality. This is a differential absorption lidar on a mobile platform designed for remote sounding of vapors of key substances used for the manufacture of explosives: acetone and nitromethane [9]. The use of spectroscopic databases and laboratory measurements showed that the 3.0-3.5 $\mu \mathrm{m}$ spectral range is optimal for differential absorption detecting $\mathrm{C}_{3} \mathrm{H}_{6} \mathrm{O}$ and $\mathrm{CH}_{3} \mathrm{NO}_{2}$ vapors [9]. The output laser pulse power is 12 $\mathrm{mJ}$, beam diameter is $22 \mathrm{~mm}$, pulse length is $5.2 \mathrm{~ns}$, pulse repetition rate is $10 \mathrm{~Hz}$, wavelength tuning time is $0.3 \mathrm{~s}$, and emission line width is $\sim 5 \mathrm{~cm}^{-1}$ [9].

Advances in the study and production of optical crystals make it possible to implement all new gas analysis systems [15 - 17] and thereby expand the possibilities of remote control of the environmental state. For example, in [18], a DIAL lidar system based on two BBO optical power amplifiers pumped by an Nd:YAG laser (pulse length of $\sim 3 \mathrm{~ns}$, pulse repetition rate of up to $100 \mathrm{~Hz}$, and the tuning range $0.4-2.5 \mu \mathrm{m}$ ) is described. As an example, the author measured vertical distributions of water vapor at wavelengths $\lambda_{\text {on }}=1187.869 \mathrm{~nm}$ and $\lambda_{\text {off }}=1187.716 \mathrm{~nm}$ along a $1500 \mathrm{~m}$ path with a spatial resolution of $15 \mathrm{~m}$. In [19], the authors used a LiNbO3 crystal pumped with an $\mathrm{Nd}: Y A G+3$ laser to implement a gas analysis system with laser wavelength tuning ranges 1.41-1.85 and 2.9-4.1 $\mu \mathrm{m}$, output power of 1-45 mJ, and radiation line width of 3-3.5 $\mathrm{cm}^{-1}$. The technical characteristics of the system point out to a possibility of detecting $\mathrm{CH}_{4}$ with a path-integral sensitivity of $1 \mathrm{ppm}$ using topographic targets at distances of $2-5 \mathrm{~km}$. The use of a OPO DIAL system based on KTP with Nd:YAG pumping (output power of 70-100 mJ per pulse) [20] allowed the authors to measure daily fluctuations of $\mathrm{CO}_{2}$ at a wavelength of $1.57 \mu \mathrm{m}$.

The authors of [21] presented a laser source on crystals with a periodic domain structure radiating in the range 3.3-3.7 $\mu \mathrm{m}$. The authors report that this radiation source allows simultaneously detection of $\mathrm{H}_{2} \mathrm{O}$ and $\mathrm{CH}_{4}$. In the recent work [22], a similar system with working wavelengths near $2 \mu \mathrm{m}$ is described in more details. The use of $\mathrm{LiNbO} 3$ crystals with a periodic domain structure allows one to study the concentrations of such gases as $\mathrm{CO}_{2}, \mathrm{CH}_{4}$, and $\mathrm{H}_{2} \mathrm{O}$ and is a step in the design of a multicomponent gas analysis system based on a similar radiation source [22]. In work [23], the results of development of a system with a diode-pumped Nd:YLF laser and an KTP-based OPO. Using it, the authors successfully measured path-integral carbon dioxide concentration (path length is $\sim 2 \mathrm{~km}$ ). As a result of further research [24], a system capable of in-field automatic detection of $\mathrm{CO}_{2}$ and $\mathrm{CH}_{4}$ in three dimensions has been designed [24].

The OPO DIAL lidar systems described above work either in the near or in the middle IR region of the spectrum.

The aims of this work are the design and test in numerical and field experiments of a DIAL OPO lidar system based on KTA and KTP crystals, which allow laser radiation tuning both in the near and in the middle IR spectral region.

\section{Materials and Methods}

\subsection{DIAL Technique}

The fundamental operating principle of DIAL is that part of the backscattered laser radiation is transformed by the molecules and aerosol particles as it passes through the atmosphere. The laser beam is attenuated (in accordance with the Lambert-Beer law) by molecular absorption and molecular and aerosol scattering. The signal recorded by the detector is thus a function of this 
attenuation, the fraction of backscattered photons, the path length, and the laser radiation power. The signal from a scattering layer of thickness $\Delta z$ can be written as

$$
P_{\mathrm{R}}(z, \lambda)=P_{0}(\lambda) \frac{A_{\mathrm{D}}}{z^{2}} \eta(\lambda) O(z) \Delta z \beta(z, \lambda) e^{[-2 \tau(z, \lambda)]},
$$

where $P_{0}(\lambda)$ is the power of the laser radiation, $A_{D}$ is the area of the detector telescope, $O(z)$ is the overlap region between the laser beam and the detector's field of view, $\beta(\mathrm{z} ; \lambda)$ is the volume backscattering coefficient of the radiation, $\eta(\lambda)$ is the efficiency of the detector-transmitter system, $\Delta z$ is the spatial resolution over the probe track, $\tau(z ; \lambda)$ is the volume attenuation coefficient, and $z$ is the distance from the detector to the point where the optical axis crosses the laser beam [the probe track length obeys $\mathrm{z}^{2}$ « $\mathrm{O}(\mathrm{z})$ ]. The DIAL consists of determining the concentration of an atmospheric gas from the difference of the lidar signals at the on- and off-wavelengths with different molecular absorption.

The concentration of the gas of interest is determined from

$$
n(z)=\frac{1}{2 \Delta \sigma_{\text {abs }} \Delta z} \ln \left(\frac{P_{\mathrm{R}}\left(z, \lambda_{\text {on }}\right) P_{\mathrm{R}}\left(z+\Delta z, \lambda_{\text {off }}\right)}{P_{\mathrm{R}}\left(z, \lambda_{\text {off }}\right) P_{\mathrm{R}}\left(z+\Delta z, \lambda_{\text {on }}\right)}\right),
$$

where $\Delta \sigma_{\text {abs }}$ is the absorption cross section.

It is well known that the expression for the minimum detectable concentrations in experiments that use differential absorption with lidar probing has the following form [25]:

$$
N(z)=\frac{\ln P\left(v_{\mathrm{ON}}, z\right)-\ln P\left(v_{\mathrm{OFF}}, z\right)}{2 \Delta K(v) z},
$$

where $\mathrm{P}\left(\mathrm{voN}_{\mathrm{O}} ; \mathrm{z}\right)$ and $\mathrm{P}\left(\mathrm{vofF}_{\mathrm{O}} ; \mathrm{z}\right)$ are the signals recorded by the photodetector from a probing track with length $\mathrm{z}$ at frequencies voN and voff, located in the narrow spectral range of the absorption line of the gas of interest and in the adjacent window of transparency, while

$$
\Delta K(v)=K\left(v_{\mathrm{ON}}\right)-K\left(v_{\mathrm{OFF}}\right),
$$

is the differential absorption coefficient, where $\mathrm{K}\left(v_{\mathrm{ON}}\right)$ and $\mathrm{K}\left(v_{\mathrm{OFF}}\right)$ are the absorption coefficients within and outside the absorption line. For most of the actual devices experimentally used for recording and digital processing, the difference of logarithms in Eq. (4) must satisfy the condition [25]

$$
\ln P\left(v_{\mathrm{ON}}, z\right)-\ln P\left(v_{\mathrm{OFF}}, z\right) \approx 0.02 \text {. }
$$

Using Eq. (5), the minimum intensities of the absorption lines can be determined by modeling and comparing the transmission spectra of an atmosphere of the gaseous components with the interfering components.

\subsection{OPO DIAL Lidar Numerical Simulation}

The technique developed [26 - 29] for lidar measurements of trace atmospheric gases (TAGs) has been tested in numerical experiments to estimate the level of lidar signals when using the KTA/KTP-based OPO laser system. Possibilities of sounding certain TAGs along surface tropospheric paths in the spectral regions under study have been analyzed.

During the numerical simulation, parameters of the DIAL system, which provides for tunable generation of nanosecond radiation pulses in the 1.8-2.5 and 3-4 $\mu \mathrm{m}$ spectral ranges, are used, as well as the parameters of the receiving telescope and InAs/InAsSbP photodiodes. The main components of the laser system are:

- LQ529B Nd:YAG pulsed laser;

- radiation converter with the wavelength tuning range 1.8-2.5 $\mu \mathrm{m}$;

- radiation converter with the wavelength tuning range $3-4 \mu \mathrm{m}$; 
- step motor (SM) controlling the wavelength;

- SM controller;

- S100 spectrometer;

- Common base for the laser and converter with a system for guiding pumping radiation in the converter.

The main parameters of the pumping laser and radiation converters are given in Tables 1-3.

Table 1. Specification of the LQ529B pumping laser.

\begin{tabular}{cc}
\hline Parameter & Value \\
\hline Pulse frequency & $10 \mathrm{~Hz}$ \\
Output energy: at $1064 \mathrm{~nm}$ & $350 \mathrm{~mJ}$ \\
Pulse length at $1064 \mathrm{~nm}, \mathrm{FWHM}$ & $10 \ldots 13 \mathrm{~ns}$ \\
Beam diameter at $1064 \mathrm{~nm}$ & $\leq 6 \mathrm{~mm}$ \\
Beam divergence at $1064 \mathrm{~nm}$ & $\sim 1.5 \mathrm{mrad}$ \\
Stability of pulse energy at $1064 \mathrm{~nm}$, & $\pm 2.5 \%$ \\
better than & \\
\hline
\end{tabular}

Table 2. Specification of the radiation converter in the $1.8-2.5 \mu \mathrm{m}$ wavelength tuning range.

\begin{tabular}{cc}
\hline Parameter & Value \\
\hline Pulse energy, in the tuning curve peak & $23 \mathrm{~mJ}$ \\
Pulse frequency & $10 \mathrm{~Hz}$ \\
Radiation divergence & $2 \mathrm{mrad}$ \\
Wavelength tuning control & with 3 SMs \\
\hline
\end{tabular}

Table 3. Specification of the radiation converter in the 3-4 $\mu \mathrm{m}$ wavelength tuning range.

\begin{tabular}{cc}
\hline Parameter & Value \\
\hline Pulse energy, in the tuning curve peak & $9 \mathrm{~mJ}$ \\
Pulse frequency & $10 \mathrm{~Hz}$ \\
Radiation divergence & $2 \mathrm{mrad}$ \\
Wavelength tuning control & with 3 SMs \\
\hline
\end{tabular}

The lidar system designed allows narrowing the laser radiation line to $0.5-1 \mathrm{~cm}^{-1}$.

We simulated the atmospheric transmission and calculated lidar signals in the 3-4 $\mu \mathrm{m}$ spectral range in the standard summer mid-latitude model of the atmosphere [30]. The interfering absorption of all main atmospheric gases was considered. The input data for the numerical simulation are given in Table 4, the concentration of a component to be sounded has been assumed to be no less than 1 ppm.

Table 4. Input data for numerical simulation of laser sounding.

\begin{tabular}{cc}
\hline Parameter & Value \\
\hline Receiver area Arec. $(\mathrm{D}=0.3 \mathrm{~m})$ & $7 \cdot 10^{-8} \mathrm{~km}^{2}$ \\
Instrumental function width & $0.1 ; 1 \mathrm{~cm}^{-1}$ \\
Receiving system efficiency & 0.3 \\
Spatial resolution $\Delta R$ & 0.2 и $1 \mathrm{~km}$ \\
Pulse energy maximum & $9 \mathrm{~mJ}$ \\
Pulse frequency & $10 \mathrm{~Hz}$ \\
Pulse length & $10-13 \mathrm{~ns}$ \\
Radiation divergence & $2 \mathrm{mrad}$ \\
Photodetector NEP & $1 \cdot 10^{-12} \mathrm{~W}$ \\
\hline
\end{tabular}

Calculated informative wavelengths suitable for sounding $\mathrm{HCN}$ and $\mathrm{C}_{2} \mathrm{H}_{6}$ at an instrumental function width of $0.1 \mathrm{~cm}^{-1}$ are given in Table 5 . 
Table 5. Wavelength suitable for sounding $\mathrm{HCN}$ and $\mathrm{C}_{2} \mathrm{H}_{6}(\Delta R=0.2 \mathrm{~km})$.

\begin{tabular}{|c|c|c|c|c|}
\hline Gas & $\lambda_{\mathrm{abs},} \mu \mathrm{m}$ (in air) & Vabs, cm $^{-1}$ (in air) & $T_{\text {gas }}$ & $T_{\text {dist }}$ \\
\hline \multirow{4}{*}{$\mathrm{HCN}$} & 3.05977 - on-line & 3268.214 & 0.72 & 0.96 \\
\hline & 3.05998 - off-line & 3267.994 & 0.89 & 0.96 \\
\hline & 3.00158 - on-line & 3331.574 & 0.62 & 0.97 \\
\hline & 3.00144 - off-line & 3331.724 & 0.79 & 0.96 \\
\hline \multirow{8}{*}{$\mathrm{C}_{2} \mathrm{H}_{6}$} & 3.33202 - on-line & 3001.177 & 0.50 & 0.98 \\
\hline & 3.33228 - off-line & 3000.947 & 0.93 & 0.99 \\
\hline & 3.33583 - on-line & 2997.746 & 0.37 & 0.97 \\
\hline & 3.33560 - off-line & 2998.027 & 0.86 & 0.98 \\
\hline & 3.36029 - on-line & 2975.934 & 0.45 & 0.95 \\
\hline & 3.36108 - off-line & 2975.234 & 0.92 & 0.96 \\
\hline & 3.35832 - on-line & 2977.671 & 0.45 & 0.95 \\
\hline & 3.35852 - off-line & 2977.501 & 0.79 & 0.95 \\
\hline
\end{tabular}

The spatially and spectrally resolved lidar signals for $\mathrm{HCN}$ and $\mathrm{C}_{2} \mathrm{H}_{6}$ calculated for a horizontal tropospheric path in the 3-4 $\mathrm{m}$ spectral range are shown in Fig. 1. Based on the atmospheric transmission simulation results (Table 5 and Fig. 5), we have selected sounding wavelength ranges (Fig. 1) of high information content for the analysis of $\mathrm{HCN}$ and $\mathrm{C}_{2} \mathrm{H}_{6}$.
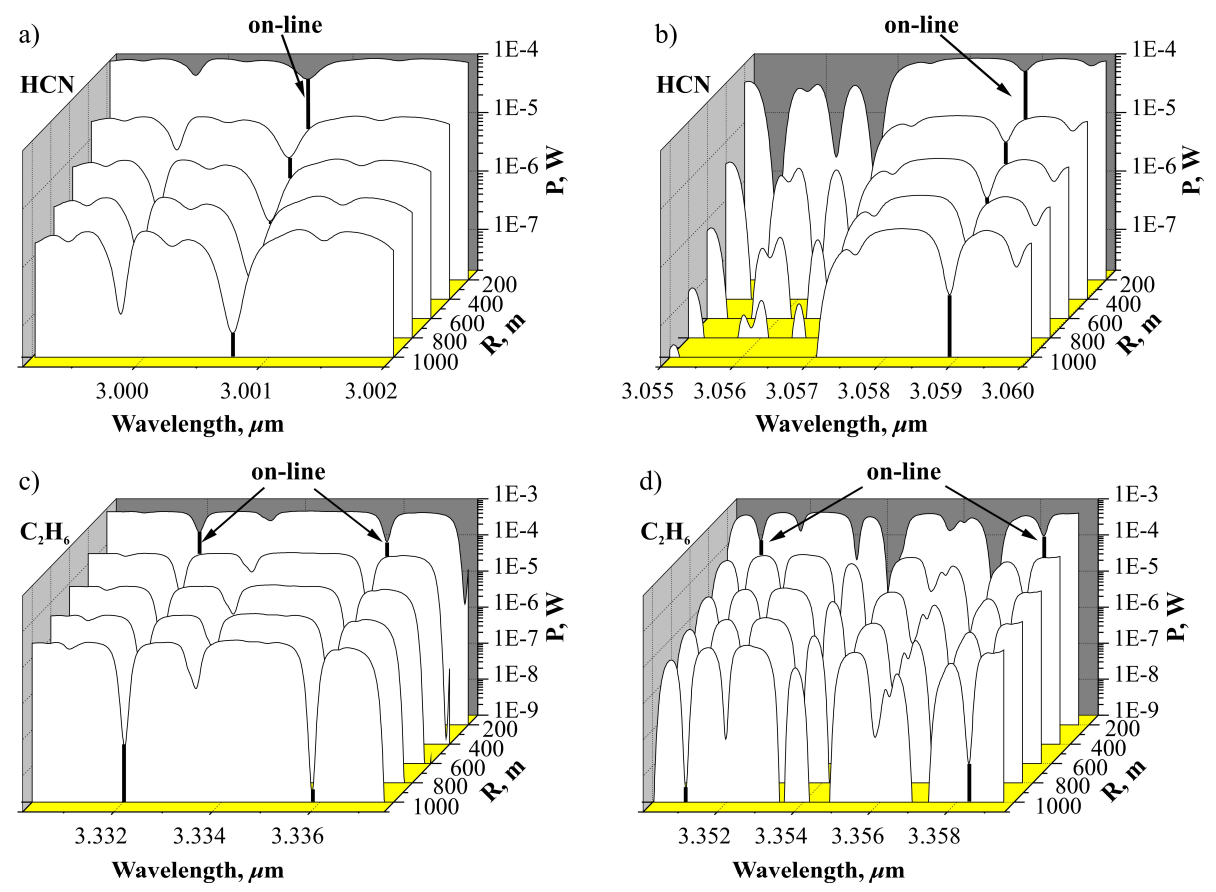

Figure 1. Spatially and spectrally resolved lidar signals of $\mathrm{HCN}(\mathrm{a}, \mathrm{b})$ and $\mathrm{C}_{2} \mathrm{H}_{6}(\mathrm{c}, \mathrm{d})$ horizontal sounding in the range of operation of the KTA-based OPO (instrumental function width is $0.1 \mathrm{~cm}^{-1}$ ).

The informative wavelengths applicable to the methane sounding are given in Table 6 (instrumental function width is $1 \mathrm{~cm}^{-1}$ ).

The spatially and spectrally resolved lidar signals for $\mathrm{CH}_{4}$ calculated for a vertical tropospheric path in the 3-4 $\mu \mathrm{m}$ spectral range are shown in Fig. 2.

Based on the atmospheric transmission simulation results, sounding range (Table 6 and Fig. 2) of high information content for the methane gas analysis $(3.38-3.48 \mu \mathrm{m})$ have been distinguished. 
Table 6. Wavelength suitable for sounding $\mathrm{CH}_{4}(\Delta R=1 \mathrm{~km})$.

\begin{tabular}{ccccc}
\hline Gas & $\boldsymbol{\lambda}_{\text {abs, }} \boldsymbol{\mu}$ m (in air) & Vabs, $\mathbf{~ c m}^{-\mathbf{1}}$ (in air) & $\boldsymbol{T}_{\text {gas }}$ & $\boldsymbol{T}_{\text {dist }}$ \\
\hline & 3.46490 - on-line & 2886.078 & 0.86 & 0.91 \\
& 3.46395 - off-line & 2886.877 & 0.90 & 0.93 \\
& 3.42746 - on-line & 2917.607 & 0.60 & 0.72 \\
$\mathrm{CH}_{4}$ & 3.42962 - off-line & 2915.774 & 0.98 & 0.98 \\
& 3.41537 - on-line & 2927.932 & 0.46 & 0.61 \\
& 3.41716 - off-line & 2926.406 & 0.93 & 0.94 \\
& 3.39101 - on-line & 2948.970 & 0.32 & 0.46 \\
& 3.38844 - off-line & 2951.210 & 0.97 & 0.97 \\
\hline
\end{tabular}

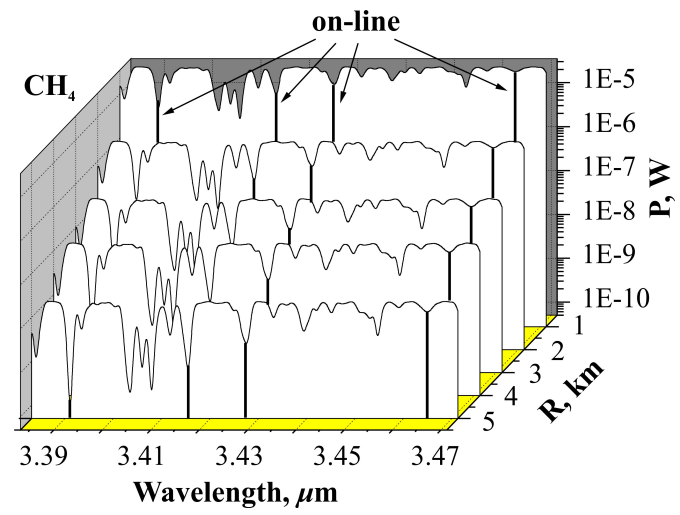

Figure 2. Spatially and spectrally resolved lidar signals of $\mathrm{CH}_{4}$ vertical sounding in the 3-4 $\mu \mathrm{m}$ spectral range (instrumental function width is $1 \mathrm{~cm}^{-1}$ ).

To estimate a possibility of sounding TAGs along horizontal paths in the range of generation of an OPO laser tunable in the 1.8-2.5 $\mu \mathrm{m}$ spectral range, the atmospheric transmission has been simulated and lidar signals have been calculated similar to the 3-4 $\mu \mathrm{m}$ spectral range. The input data of the numerical simulation are also similar to the input data given in Table 4, except for the pulse energy maximum, which is $23 \mathrm{~mJ}$ in this case. The calculations have been carried out with the instrumental function equal to $1 \mathrm{~cm}^{-1}$. The concentration of $\mathrm{H}_{2} \mathrm{O}$ has been assumed to be no less than $15600 \mathrm{ppm}$, and of $\mathrm{CO}_{2}$, than $380 \mathrm{ppm}$. Table 7 shows the calculated informative wavelengths suitable for sounding $\mathrm{CO}_{2}$ and $\mathrm{H}_{2} \mathrm{O}$.

Table 7. Wavelength suitable for sounding $\mathrm{CO}_{2}$ and $\mathrm{H}_{2} \mathrm{O}(\Delta R=1 \mathrm{~km})$.

\begin{tabular}{ccccc}
\hline Gas & $\lambda_{\text {abs, }} \boldsymbol{\mu}$ m (in air) & Vabs, $\mathbf{~ c m}^{-\mathbf{1}}$ (in air) & $\boldsymbol{T}_{\text {gas }}$ & $\boldsymbol{T}_{\text {dist }}$ \\
\hline & 2.0026 - on-line & 4993.460 & 0.28 & 0.50 \\
& 1.9994 - off-line & 5001.463 & 0.70 & 0.95 \\
$\mathrm{CO}_{2}$ & 2.0123 - on-line & 4969.253 & 0.40 & 0.68 \\
& 2.0086 - off-line & 4978.456 & 0.92 & 0.98 \\
& 2.0561 - on-line & 4863.422 & 0.76 & 0.88 \\
& 2.0587 - off-line & 4857.420 & 0.94 & 0.99 \\
\hline $\mathrm{H}_{2} \mathrm{O}$ & 2.1629 - on-line & 4623.352 & 0.72 & 0.99 \\
& 2.1648 - off-line & 4619.351 & 0.97 & 0.99 \\
& 2.1837 - on-line & 4579.339 & 0.71 & 0.98 \\
& 2.1861 - off-line & 4574.338 & 0.99 & 0.99 \\
& 2.1976 - on-line & 4550.331 & 0.76 & 0.99 \\
& 2.2000 - off-line & 4545.329 & 0.96 & 0.98 \\
\hline
\end{tabular}


2 of 12

The spatially and spectrally resolved lidar signals for $\mathrm{CO}_{2}$ and $\mathrm{H}_{2} \mathrm{O}$ calculated for a horizontal tropospheric path in the 1.8-2.5 $\mu \mathrm{m}$ spectral range are shown in Fig. 3.

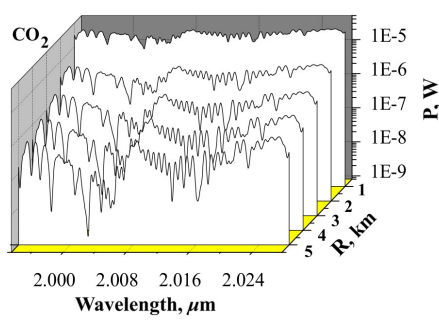

a)

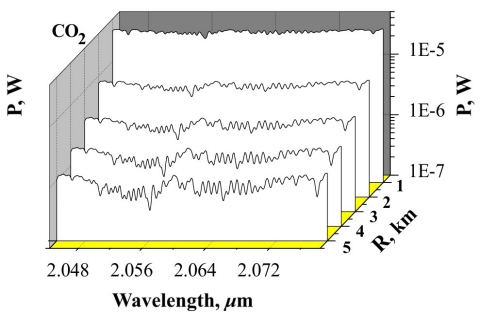

b)

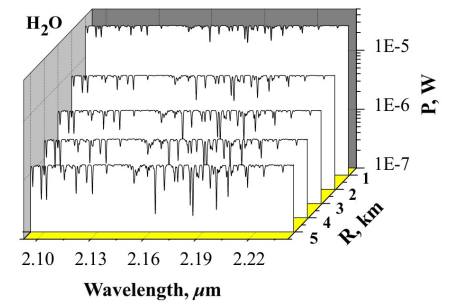

c)

Figure 3. Spatially and spectrally resolved lidar signals of (a and b) $\mathrm{CO}_{2}$ and (c) $\mathrm{H}_{2} \mathrm{O}$ horizontal sounding in the $1.8-2.5 \mu \mathrm{m}$ range (instrumental function width is $1 \mathrm{~cm}^{-1}$ ).

Based on the atmospheric transmission simulation results, sounding ranges (Fig. 3) of high information content for $\mathrm{H}_{2} \mathrm{O}(2.10-2.24 \mu \mathrm{m})$ and $\mathrm{CO}_{2}(1.995-2.025$ and 2.045-2.075 $\mu \mathrm{m})$ gas analysis have been distinguished.

Figures 1-3 show that the level of lidar signals exceeds the level of photoreceiver noise equivalent power $\mathrm{NEP}=10^{-12} \mathrm{~W}$ throughout the path length range under study.

Thus, the numerical simulation results proves a possibility of retrieving the lidar signal at horizontal paths up to $5 \mathrm{~km}$ long when sounding $\mathrm{CO}_{2}$ and $\mathrm{H}_{2} \mathrm{O}$ with the KTP-based OPO radiation in the 1.8-2.5 $\mu \mathrm{m}$ range, at vertical paths up to $5 \mathrm{~km}$ long when sounding $\mathrm{CH}_{4}$ with the KTA-based OPO radiation in the $3-4 \mu \mathrm{m}$ range, as well as a possibility of retrieving the lidar signal at horizontal paths up to $1 \mathrm{~km}$ long when sounding $\mathrm{HCN}$ and $\mathrm{C}_{2} \mathrm{H}_{6}$ vapors with the KTA-based OPO radiation.

\subsection{Near/Mid IR DIAL OPO Lidar System}

The universal scheme of the lidar system developed (Fig. 4) is used for in field atmospheric measurements in the spectral range 3-4 $\mu \mathrm{m}$ and $1.8-2.5 \mu \mathrm{m}$.

A LQ529B Nd:YAG laser acts as a master oscillator; it generates laser pulses of 10-13 ns in length and $350 \mathrm{~mJ}$ in energy at a frequency of $10 \mathrm{~Hz}$ at a wavelength of $1.064 \mu \mathrm{m}$. The radiation converter includes a narrowband master KTP-based OPO pumped by second-harmonic radiation at $0.532 \mu \mathrm{m}$ and a KTA-based OPO pumped by radiation at $1.064 \mu \mathrm{m}$.

The master OPO generates low-power radiation with a tunable pumping wavelength in the $0.785-0.840 \mu \mathrm{m}$ and $0,710-0,755 \mu \mathrm{m}$ (signal wave $\lambda_{\mathrm{s}}$ ), and also $1.45-1.65 \mu \mathrm{m}, 1,800-2,128 \mu \mathrm{m}$ (idler wave $\lambda_{\mathrm{i}}$ ) ranges. The KTA-based OPO generates and amplifies radiation with the wavelength tunable in the region 3-4 $\mu \mathrm{m}$ and the linewidth $<2 \mathrm{~cm}^{-1}$. The KTP-based OPO generates and amplifies radiation with the wavelength tunable in the region 1.8-2.5 $\mu \mathrm{m}$ and the linewidth $<2 \mathrm{~cm}^{-1}$. The converter design provides for a possibility of mounting a narrowband injection laser diode with optical isolators to generate radiation with the linewidth $<0.1 \mathrm{~cm}^{-1}$.

During the experiments on estimation of the energy parameters of the laser system, the pulse energy maximum attained $9 \mathrm{~mJ}$ for the 3-4 $\mu \mathrm{m}$ wavelength range and $23 \mathrm{~mJ}$ for the 1.8-2.5 $\mu \mathrm{m}$ wavelength range. The dependence of the laser pulse energy on the wavelength was experimentally derived to verify the correctness of the OPO laser operation throughout the tuning frequency range and, if necessary, to align the optical components of the system.

The wavelength tuning is provided by rotating KTP and KTA crystals with three automated step motors. To control the output radiation wavelength, a S100-2048 spectrometer is used; its key parameters are given in Table 8 . The spectrometer allows estimating the wavelength $\lambda$ s of the signal wave generated by the narrowband master KTP-based OPO. Before guiding the radiation along a sounding path, a part of the output radiation is deflected by a $\mathrm{CaF}_{2}$ plate for recording the reference signal. The laser beam is bloomed with a mirror collimator, which allows reducing the angle of radiation divergence to $1 \mathrm{mrad}$. The receiving part of the lidar consists of a Cassegrain telescope (focal length $=120 \mathrm{~mm}$ ), which focuses the atmosphere-backscattered laser radiation to the 
photosensitive area $(300 \mu \mathrm{m})$ of a cooled PD36-03-TEC-PRW InAs/InAsSbP photodiode controlled by the AMT-07M amplifier. The key parameters of the devices used in the receiving part of the lidar system are given in Table 9.

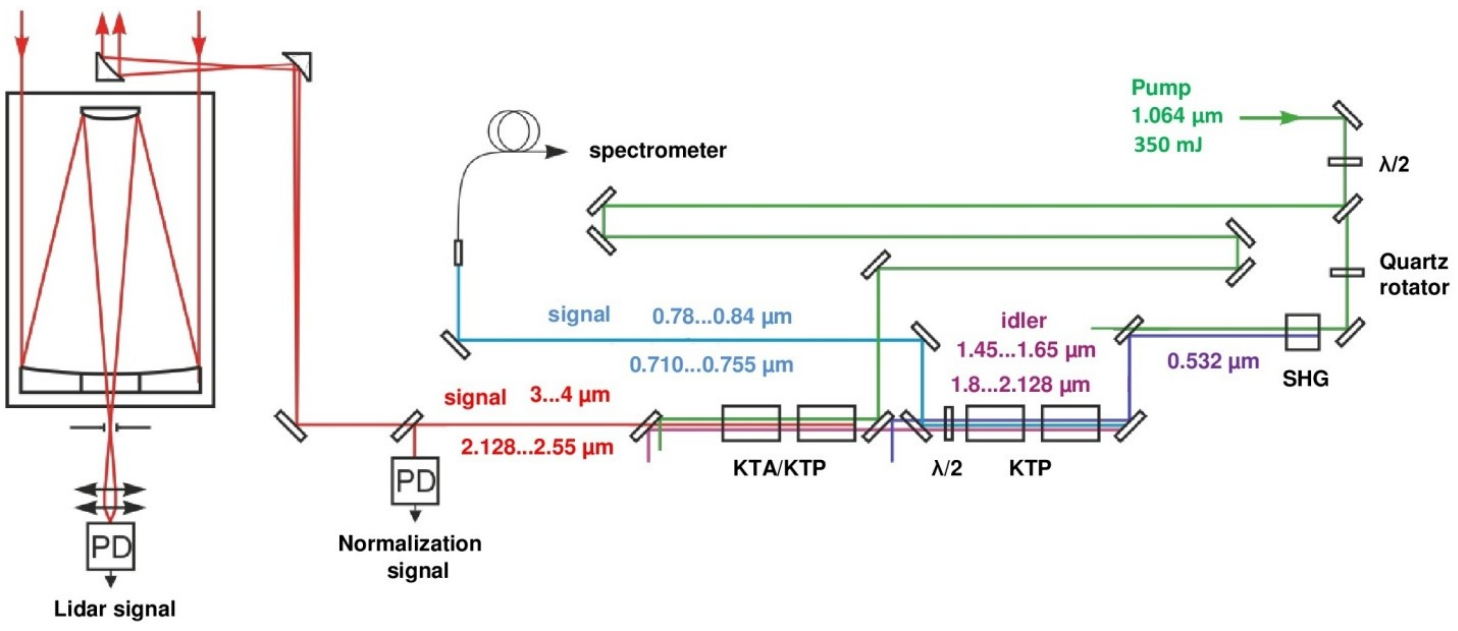

Figure 4. Near/Mid IR dIfferential absorption OPO lidar system.

Table 8. Specification of the S100-2048 spectrometer.

\begin{tabular}{cc}
\hline Parameter & Value \\
\hline Diffraction grating, gr./mm & 300 \\
Spectral range, $\mathrm{mm}$ & $200-1100$ \\
Spectral resolution, $\mathrm{nm}$ & 1.5 \\
CCD detector model & TCD1205, 2048 pixels, \\
& pixel size is $14 \mu \mathrm{m}$ \\
Light sensitive area, $\mathrm{mm}$ & $28.67 \times 0.2$ \\
ADC effective number of bits & 14 bits, 16384 counts \\
\hline
\end{tabular}

Table 9. Specification of PD36-03-TEC-PRW photodiodes.

\begin{tabular}{cc}
\hline Parameter & Value \\
\hline Spectral range, $\mu \mathrm{m}$ & $1.5-3.8$ \\
Detectability, $\mathrm{cm} \cdot \mathrm{Hz}^{1 / 2} \cdot \mathrm{Wt}^{-1}$ & $(3-6) \cdot 10^{9}$ \\
Monochromatic current sensitivity, A/W & $1.0-1.2$ \\
Rise time/Fall time, $\mathrm{ns}$ & $20-120$ \\
\hline
\end{tabular}

The signals are digitized using an 8-bit ADC TS2202E, which provides a sampling frequency of 1 Gsamp./s in all channels and a variable bandwidth up to $200 \mathrm{MHz}$.

\section{Results and Discussion}

\subsection{OPO Lidar Signal Measurement Results}

An experimental OPO lidar setup (Fig. 4) was used to estimate the limiting lengths of surface sounding paths (sounding range) from the technical parameters of the PD36-03-TEC-PRW photodiodes used in the receiving part of the lidar. In addition, echoes were experimentally recorded in the real atmosphere under discrete wavelength tuning in the 3-4 and 1.8-2.5 $\mu \mathrm{m}$ spectral range. 
Figure 5 exemplifies a lidar signals recorded with the use of the PD36-03-TEC-PRW photodiode detector prior to algorithmic processing. This atmospheric response has been recorded at a unit gain factor.

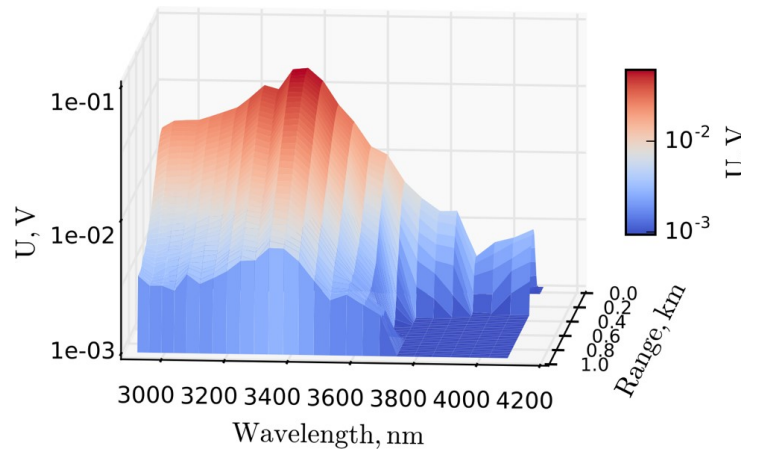

(a)

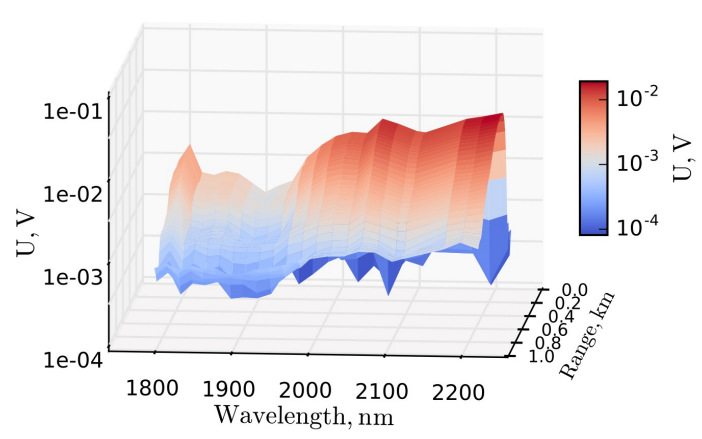

(b)

Figure 5. Lidar echoes at discrete OPO lidar radiation lines in the 3-4 $\mu \mathrm{m}$ (a) and 1.8-2.5 $\mu \mathrm{m}$ (b) spectral range.

Figure 6 exemplifies a recorded lidar echoes at one of the most powerful OPO laser radiation lines of $3.530 \mu \mathrm{m}$ and $1.984 \mu \mathrm{m}$.

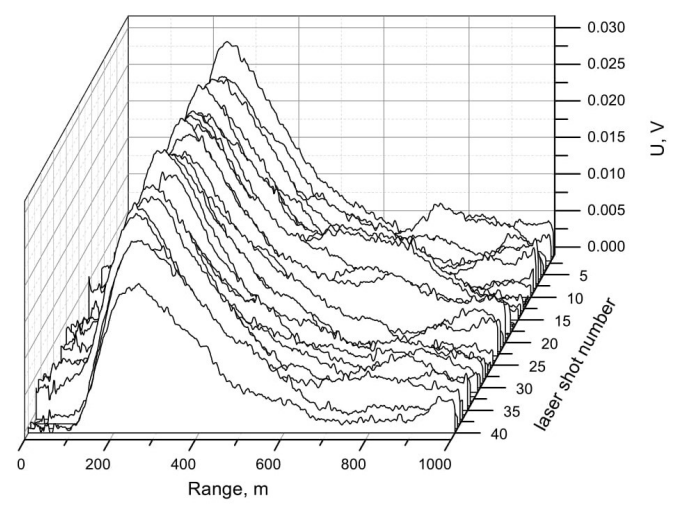

(a)

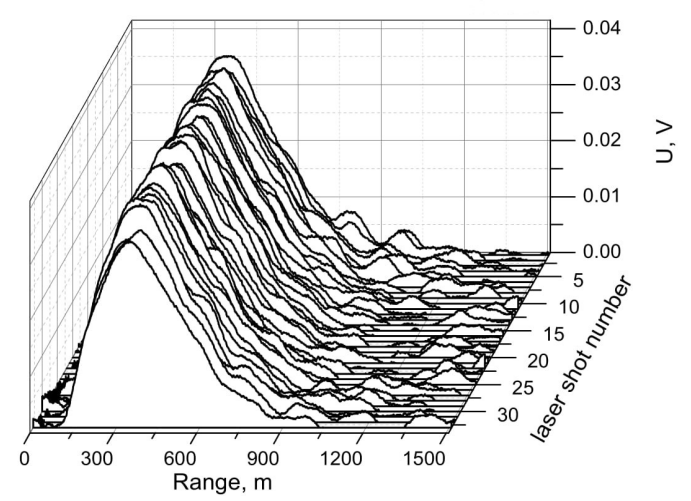

(b)

Figure 6. Lidar echoes at discrete OPO lidar radiation lines in the 3-4 $\mu \mathrm{m}$ (a) and 1.8-2.5 $\mu \mathrm{m}$ (b) spectral range.

The experimental results show a possibility of lidar sounding when using the receiving part configuration described (receiving telescope + photodiode) along paths up to $1 \mathrm{~km}$ long and $1.5 \mathrm{~km}$, respectively.

\section{2. $\mathrm{H}_{2} \mathrm{O}$ and $\mathrm{CO}_{2}$ Concentration Measurement Results}

Using the developed near/mid IR DIAL OPO lidar, field experimental studies of the distribution of $\mathrm{H}_{2} \mathrm{O}$ and $\mathrm{CO}_{2}$ concentrations in urban conditions were carried out. The measurements were carried out on a horizontal path in the city of Tomsk in the summer of 2018.

The informative wavelengths of $\mathrm{CO}_{2}$ and $\mathrm{H}_{2} \mathrm{O}$, determined as a result of numerical simulation, were used. For $\mathrm{CO}_{2}$ measurements, the first pair of wavelengths from Table 7 was used (2.0026 - on-line and 1.9994 - off-line) and for $\mathrm{H}_{2} \mathrm{O}$ measurements, the pair of wavelengths (2.1629 - on-line and 2.1648 - off-line).

Figure 7 presents examples of the time dynamics of the concentration of $\mathrm{H}_{2} \mathrm{O}$ (a) and $\mathrm{CO}_{2}(\mathrm{~b})$ along the horizontal sounding path with a length of $1750 \mathrm{~m}$. 


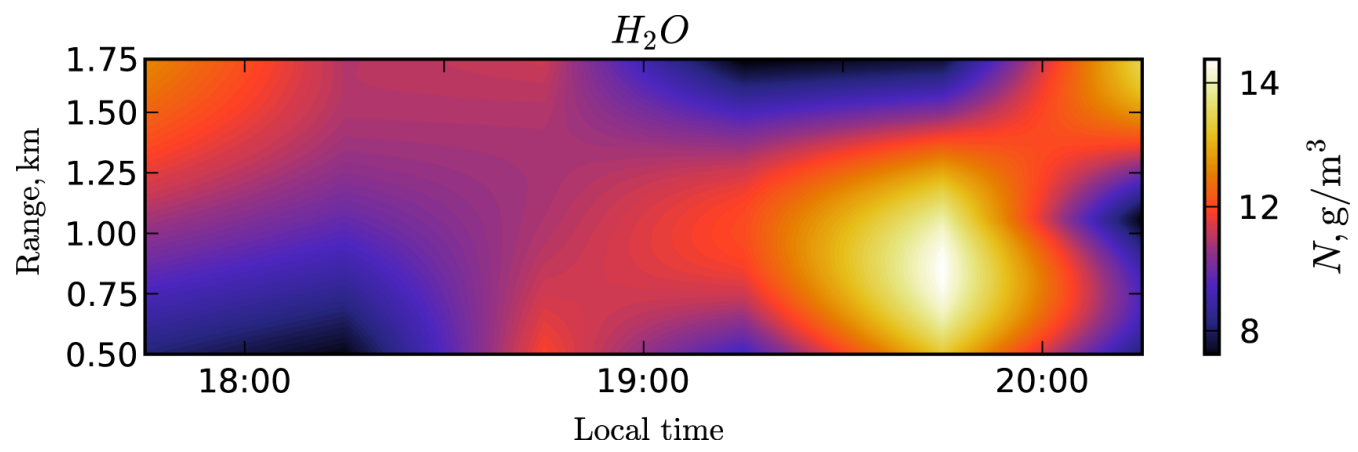

(a)

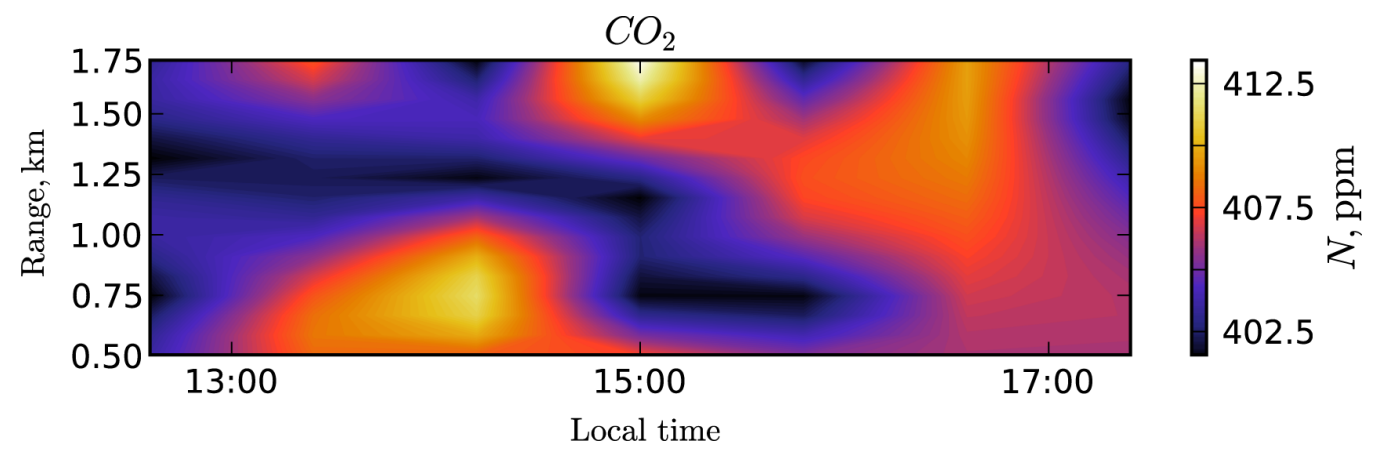

(b)

Figure 7. Results of field measurements of $\mathrm{H}_{2} \mathrm{O}(\mathrm{a})$ and $\mathrm{CO}_{2}(\mathrm{~b})$ concentration.

It can be seen from the figures that the OPO DIAL lidar system developed allows to track the time dynamics of the distribution of water vapor and carbon dioxide in the surface layer of the atmosphere.

The results of field measurements are in good agreement with the numerical simulation data and confirm the possibility of using the OPO DIAL lidar system developed to restore the concentrations of the gases being studied that are close to the background and supra-background values.

\section{Conclusions}

The results of simulation of atmospheric transmission and lidar signals show that the OPO lidar presented in this work, which covers the near/mid-IR region, is promising for remote atmospheric sounding of TAGs under study along surface tropospheric paths. The numerical simulation proves a possibility of retrieving the lidar signal at horizontal paths up to $5 \mathrm{~km}$ long when sounding $\mathrm{CO}_{2}$ and $\mathrm{H}_{2} \mathrm{O}$ with the KTP-based OPO radiation in the $1.8-2.5 \mu \mathrm{m}$ range, at vertical paths up to $5 \mathrm{~km}$ long when sounding $\mathrm{CH}_{4}$ with the KTA-based OPO radiation in the 3-4 $\mu \mathrm{m}$ range, as well as a possibility of retrieving the lidar signal at horizontal paths up to $1 \mathrm{~km}$ long when sounding $\mathrm{HCN}$ and $\mathrm{C}_{2} \mathrm{H}_{6}$ vapors with the KTA-based OPO radiation.

The universal near/mid-IR OPO DIAL lidar system developed is used for in field atmospheric measurements in the spectral range 3-4 $\mu \mathrm{m}$ and 1.8-2.5 $\mu \mathrm{m}$. During the experiments on estimation of the energy parameters of the laser system, the pulse energy maximum attained $9 \mathrm{~mJ}$ for the 3-4 $\mu \mathrm{m}$ wavelength range and $23 \mathrm{~mJ}$ for the 1.8-2.5 $\mu \mathrm{m}$ wavelength range. Experimentally recorded lidar signals confirm a possibility of the remote gas analysis of the atmosphere using the lidar system developed in the near/mid-IR wavelength ranges 1.8-2.5 and 3-4 $\mu \mathrm{m}$ along paths of up to $1.5 \mathrm{~km}$ and $1 \mathrm{~km}$ in length, respectively. 
6 of 12

The results of the water vapor and carbon dioxide concentration distribution confirm the possibility of using the created OPO DIAL lidar system to measure the content and time dynamics of gases in the surface layer of the atmosphere.

Author Contributions: Conceptualization, O.R. and S.Y.; Methodology, O.R., S.S., O.K. and S.Y.; Investigation, S.S. and O.K..; Formal analysis, O.R., S.S., O.K. and S.Y.; Data curation, O.R., S.S., O.K. and S.Y; Writing-Original Draft Preparation, S.S., O.K. and S.Y.; Writing-Review \& Editing, O.R. and S.Y.; Project Administration, O.R.; Funding Acquisition, O.R.

Funding: This research was funded by the Russian Foundation for Basic Research, (16-45-700722 - numerical simulation), the President of the Russian Federation (MK-1367.2017.5 - lidar), and by Ministry of Education of Science of RF (14.613.21.0077, unique identifier RFMEFI61317X0077 - measurements).

Conflicts of Interest: The authors declare no conflict of interest.

\section{References}

1. Weitkamp C. Lidar: range-resolved optical remote sensing of the atmosphere. Springer-Verlag: New York, USA, 2006. v. 102.

2. Vasil'ev B.I., Mannoun U.M IR differential-absorption lidars for ecological monitoring of the environment. Quantum Electronics, 2006, $36 \quad$ (9), pp. 801-820, https://doi.org/10.1070/QE2006v036n09ABEH006577.

3. Dolgii S. I., Nevzorov A. A., Nevzorov A. V., Romanovskii O. A. and Kharchenko O. V. Intercomparison of ozone vertical profile measurements by differential absorption lidar and IASI/MetOp satellite in the upper troposphere-lower stratosphere. Remote Sensing, 2017, 9(5), pp. 447-462, doi:10.3390/rs9050447.

4. Xiang, C.; Han, G.; Zheng, Y.; Ma, X.; Gong, W. Improvement of CO2-DIAL Signal-to-Noise Ratio Using Lifting Wavelet Transform. Sensors, 2018, 18, pp. 2362-2371, https://doi.org/10.3390/s18072362.

5. Koval'chuk L.V., Grezev A.N., Niz'ev V.G., Yakunin V.P., Mezhevov V.S., Goryachkin D.A., Sergeev V.V. and Kalintsev A.G. Repetitively pulsed TEA CO2 laser and its application for second harmonic generation in ZnGeP2 crystal. Quantum Electronics, 2015, $45 \quad$ (10), pp. 884-890, https://doi.org/10.1070/QE2015v045n10ABEH015648.

6. Kashin V.V., Nikolaev D.A., Rusanov S.Ya. and Tsvetkov V.B. Laser radiation frequency doubling in a single-crystal fibre based on a stoichiometric LiNbO3 crystal. Quantum Electronics, 45 (1), pp. 47 - 49 , https://doi.org/10.1070/QE2015v045n01ABEH015631.

7. Demtröder W. Laser Spectroscopy 1. Basic Principles. Springer: Berlin Heidelberg, Germany, 2014, P. 113-256.

8. Available online: https://solarlaser.com/en/devices/lasers-and-laser-systems/laser-systems/customised -laser-systems/ (accessed on 29 October 2018).

9. Mitev V., Babichenko S., Bennes J., Borelli R., Dolfi-Bouteyre A., Fiorani L., Hespel L., Huet T., Palucci A., Pistilli M., Puiu A., Rebane O., Sobolev I. Mid-IR DIAL for high-resolution mapping of explosive precursors. Proceeding of SPIE, 2013, v. 8894, p. 88940S, https://doi.org/10.1117/12.2028374.

10. Lambert-Girard S., Allard M., Piché M. et.al. Differential optical absorption spectroscopy lidar for mid-infrared gaseous measurements. Applied Optics, 2015, 54 (7), pp. 1647-1656, https://doi.org/10.1364/AO.54.001647.

11. Cadiou E., Mammez D., Dherbecourt J.-B. et.al. Atmospheric boundary layer CO2 remote sensing with a direct detection LIDAR instrument based on a widely tunable optical parametric source. Optics Letters, 2017, 42 (5), pp. 4044-4047, https://doi.org/10.1364/OL.42.004044.

12. Shibata Y., Nagasawa C., Abo M. Development of $1.6 \mu \mathrm{m}$ DIAL using an OPG/OPA transmitter for measuring atmospheric CO2 concentration profiles. Applied Optics, 2017, 56 (4), pp. 1194-1201, https://doi.org/10.1364/AO.56.001194.

13. Veerabuthiran S., Razdan A.K., Jindal M.K. et.al. Development of 3.0-3.45 mm OPO laser based range resolved and hard-target differential absorption lidar for sensing of atmospheric methane. Optics $\mathcal{E}$ Laser Technology, 2015, 73, pp. 1-5, DOI: 10.1016/j.optlastec.2015.04.007.

14. Ayrapetyan V.S., Fomin P.A. Laser detection of explosives based on differential absorption and scattering. Optics \& Laser Technology, 2018, 106, pp. 202-208, DOI: 10.1016/j.optlastec.2018.04.001. 
15. Reghunath A. T., Malhotra P., Kumar Y., Bhushan B. Design of a tunable mid-IR OPO source for DIAL detection of trace gases. Proceeding of SPIE, 2006, 6409, pp. 64091B-64091B-11, https://doi.org/10.1117/12.697916.

16. Douglass K.O.; Maxwell S.E., Plusquellic D.F.; Hodges J.T.; van Zee R.D.; Samarov D.V., Whetstone J.R. Construction of a high power OPO laser system for differential absorption LIDAR. Proceeding of SPIE, 2011. 8159, pp. 81590D-81590D-9, https://dx.doi.org/10.1117/12.894089.

17. Barrientos-Barria J., Dherbecourt J., Raybaut M., Godard A., Melkonian J.M., Lefebvre M.H., Faure B., Souhaite G. 3.3-3.7 $\mu \mathrm{m}$ Nested cavity OPO pumped by an amplified micro-laser for portable DIAL. 2013 Conference on Lasers \& Electro-Optics Europe \& International Quantum Electronics Conference. IEEE, 2013. 978-1-4799-0594-2. P. 1.

18. Amoruso S., Amodeo A., Armenante M., Boselli A., Mona L., Pandolfi M., Pappalardo P., Velotta R., Spinelli N., Wang X. Development of a tunable IR lidar system. Optics and lasers in engineering, 2002, 37 (5), pp. 521-532, https://doi.org/10.1016/S0143-8166(01)00115-4.

19. Ayrapetyan V. S. Measurement of absorption spectra for atmospheric methane by a lidar system with tunable emission wavelength in the range 1.41-4.24 $\mu \mathrm{m}$. Journal of Applied Spectroscopy, 2009, 76 (2), pp. 268-272, https://doi.org/10.1007/s10812-009-9152-8.

20. Amediek A., Fix A., Wirth M., Ehret G. Development of an OPO system at $1.57 \mu \mathrm{m}$ for integrated path DIAL measurement of atmospheric carbon dioxide. Applied Physics B, 2008, 92 (2), pp. 295-302, https://doi.org/10.1007/s00340-008-3075-6.

21. Barrientos-Barria J., Alexandre Dobroc A., Coudert-Alteirac H., Raybaut M., Cezard N., Dherbecourt J.-P., Faure B., Souhaité G., Melkonian J.-M., Godard A., Lefebvre M., and Pelon J. 3.3-3.7 $\mu \mathrm{m}$ OPO/OPA optical source for multi-species 200m range Integrated Path DIfferential Absorption Lidar. Applications of Lasers for Sensing and Free Space Communications, Optical Society of America, 2013. P. LTh1B. 4.

22. Mammez D., Cadiou E., Dherbecourt J.-P., Raybaut M., Melkonian J.-M., Godard A., Gorju G., Pelon J., Lefebvre M. Multispecies transmitter for DIAL sensing of atmospheric water vapour, methane and carbon dioxide in the $2 \mu \mathrm{m}$ region. Proceeding of SPIE, 2015, 9645, pp. 964507-964507-9, https://doi.org/10.1117/12.2194754.

23. Robinson I., Jack J.W., Rae C.F., Moncrieff J.B. Development of a laser for differential absorption lidar measurement of atmospheric carbon dioxide. Proceeding of SPIE, 2014, 9246, pp. 92460U-92460U-6, https://doi.org/10.1117/12.2068023.

24. Robinson I., Jack J.W., Rae C.F., Moncrieff J.B. A robust optical parametric oscillator and receiver telescope for differential absorption lidar of greenhouse gases. Proceeding of SPIE, 2015, v. 9645, pp. 96450U-96450U-7, https://doi.org/10.1117/12.2197251.

25. Collis R.T.H. and Russell P.B. Lidar Measurement of Particles and Gases by Elastic Backscattering and Differential Absorption. In: Laser Monitoring of the Atmosphere, Ed. E.D., Hinkley, Springer: New York, 1976, pp. 91-180.

26. Romanovskii O.A., Kharchenko O.V., Yakovlev S.V. Methodical Aspects of Lidar Sensing of Trace Gases in Atmosphere by Differential Absorption Method. Journal of Applied Spectroscopy, 2012, 79 (5), pp. 799-806, DOI: 10.1007/s10812-012-9673-4.

27. Bochkovskii D.A., Matvienko G.G., Romanovskii O.A., Kharchenko O.V., Yakovlev S.V. Laser Remote Measurements of Atmospheric Gas Components by Dial: Modeling and Experiments. Optical Memory and Neural Networks (Information Optics), 2014, 23 (3), pp. 156-163, https://doi.org/10.3103/S1060992X14030084.

28. Romanovskii, O.A., Sadovnikov, S.A., Kharchenko, O.V., Shumskii, V.K., Yakovlev, S.V. Application of Optical Parametric Generator for Lidar Sensing of Minor Gas Components of the Atmosphere in 3-4 $\mu \mathrm{m}$ Spectral Range. Russian Physics Journal, 201659 (3), pp. 380-386, DOI: 10.1007/s11182-016-0783-y.

29. Matvienko G.G., Romanovskii O.A., Sadovnikov S.A. et.al. Study of the possibility of using a parametric-light-generator-based laser system for lidar probing of the composition of the atmosphere. Journal of Optical Technology, 2017, 84 (6), pp. 408-414. https://doi.org/10.1364/JOT.84.000408.

30. Zuev V. E., Komarov V. S. Statistic models of temperature and gas components of the atmosphere. Springer: New York, 1992, 320 p. 